* Graduado em Direito pela Universidade Federal de Juiz de Fora

E-mail: diegome90@gmail.com

** Doutora em Direito Público pela Universidade Federal de Minas Gerais. Mestrado em Direito Administrativo pela Universidade Federal de Minas Gerais. Atualmente é Professora Adjunta de Direito Constitucional e Administrativo da Universidade Federal de Juiz de Fora, Pesquisadora, Professora do Mestrado em Direito e Inovações da Faculdade de Direito da UFJF e ex-procuradora do Município de Juiz de Fora.

E-mail:lg.melquiades@uol.com. br

\section{Desclassificação De Candidato Aprovado Em Concurso Público Tendo Por Base limitações De EXAMES MÉdicos}

\author{
The Candidate Disqualification Approved In Public \\ Tender For Taking Exams Limitations Of Basic \\ MEDICAL
}

\section{Diego Miranda Esteves* Luciana Gaspar Melquíades Duarte**}

Como citar: ESTEVES, Diego Miranda; DUARTE, Luciana Gaspar Melquíades. A desclassificação de candidato aprovado em concurso público tendo por base limitações de exames médicos. Revista do Direito Público, Londrina, v. 13, n. 3, p. 24-40, dez. 2018. DOI: $10.5433 / 24157-108104-1.2018 v 13 n 3$ p 24. ISSN: 1980-511X.

Resumo: O presente artigo objetivou analisar os limites de exames médicos como causa de desclassificação de candidato aprovado em concurso público, apontando a importância de se ter embasamento legal para sua solicitação, bem como que sejam pertinentes ao exercício dos cargos públicos em questão. Como arcabouço teórico, foi utilizado o Pós-Positivismo, precisamente a Teoria dos Princípios e a Teoria da Argumentação Jurídica (ALEXY, 2008, 2011). Foram revisitados também o Decreto $n^{\circ}$ 6.944 (BRASIL, 2009), relativo às normas gerais de concursos públicos e a Lei $n^{\circ} 8.112$ (BRASIL, 1990), que dispõe sobre o Estatuto dos Servidores Públicos Federais. Por fim, foram apontados os limites jurídicos do exame médico como etapa eliminatória, e apresentados exemplos de decisões judiciais referentes à problemática estudada.

Palavras-Chave: Concurso público; Exames médicos; PósPositivismo; Igualdade; Proporcionalidade.

Abstract: This paper analyzes the limits of medical examinations as a cause for disqualification of candidates approved for civil service positions. Thusly, this research points out the legal consequences of this practice and questions the relevance of these exams in specific fields. This study uses as its theoretical framework post-positivism, more precisely the Theory of Principles and Legal Argumentation (Alexy, 2008, 2011). This paper also examines Decree No. 6.944 (BRASIL, 2009), regarding the general rules of 
public procurement and Law No. 8.112 (BRAZIL, 1990), which is the Brazilian Statute of Public Servants. Finally, this research concludes that medical examinations are utilized as a knockout stage in order to eliminate candidates; this practice is analyzed in some judicial decisions that are also investigated in this paper.

Keywords: PubPublic tender; Medical examinations; PostPositivism; Equality. Proportionality. 


\section{INTRODUÇÃO}

Este artigo visa analisar os limites do exame médico como motivo de desclassificação de candidato aprovado em concurso público. Pretende demonstrar que determinados exames mostram-se desnecessários e vão de encontro ao que é disposto pela Constituição (BRASIL, 1988) e na lei que institui o cargo público a ser provido através do certame.

O concurso público representa importante instituto de Direito Público no Brasil. O legislador constituinte de 1988 empenhou-se em desenvolver métodos que tivessem como objetivo o ingresso de pessoal capacitado na Administração Pública, considerando a importância e a natureza dos serviços prestados para a sociedade.

O instituto do concurso foi configurado como via de provimento originário democrático de cargos públicos desde a vigência de constituições anteriores, como exemplo a Constituição (BRASIL, 1934), que, mesmo deficiente, representava uma forma embrionária do instituto.

O assunto torna-se muito relevante, pois se tem observado a má formulação de alguns editais, que se encontram em desacordo com o estabelecido na Constituição (BRASIL, 1988) e ao Decreto $\mathrm{n}^{\circ} 6.944$ (BRASIL, 2009), e geram como consequência disputas judiciais entre candidatos e a Administração Pública.

O problema será desenvolvido sob a perspectiva pós-positivista, tendo como elemento principal a Teoria dos Princípios, a diferenciação entre princípios e regras e sua estrutura normativa. Terá como referência a Teoria dos Direitos Fundamentais e a Teoria da Argumentação Jurídica, ambas na obra de Alexy $(2008,2011)$. Utilizando-se a metodologia de pesquisa bibliográfica e através do emprego do método dedutivo e, por vezes outras, indutivo, será demonstrado que exames médicos que não guardam correspondência com o cargo a ser exercido pelo candidato aprovado em concurso público não podem ser exigidos. Por fim, serão utilizados julgados com o objetivo de corroborar o ponto de vista apresentado.

\section{A INFLUÊNCIA DO PÓS POSITIVISMO}

O Pós-Positivismo surgiu como uma nova teoria relacionada à normatividade dos princípios, após a superação das ideias filosóficas do jusnaturalismo e da derrocada do Positivismo Jurídico apoiado pelos Estados nazi-fascistas no período entre 1920 a 1945.

O jusnaturalismo, ou Direito Natural, é uma teoria fundamentada no Direito independente da vontade humana, sendo tal Direito baseado nos valores dos seres humanos, com vista à busca por um ideal de justiça. O Direito Natural é legitimado por uma ética superior e estabelece limites à norma estatal, tendo validade em si (BARROSO, 2011).

O Positivismo Jurídico, ao contrário, destaca-se pela ideia de supremacia do Direito Positivo, pelo formalismo e a estatalidade do Direito. Sua principal característica é a afinidade entre Direito e norma, livre de qualquer influência sociológica ou juízos valorativos. É concebido como o conjunto das normas escritas, criadas por homens através do Estado ou de fontes por ele legitimadas.

Desta forma, foi necessário o aparecimento de uma nova formulação do Direito, não com o objetivo de negar totalmente a importância do Direito Positivo, mas submetê-lo a um juízo de valores. O Pós-Positivismo visa estabelecer uma relação entre Direito e Ética, com o objetivo de materializar a relação entre princípios, valores, regras e a Teoria dos Direitos Fundamentais. Visa também dar aos princípios jurídicos caráter normativo, para que estes atuem como uma espécie de norma jurídica vinculante.

Para o Pós-Positivismo, os princípios possuem normatividade e caracterizam-se como mandados de otimização, passíveis de concreção em diversos níveis, uma vez que sujeitos, com muita frequência, à colisão, que exige o emprego da técnica da ponderação para ser solucionada. 
Tal teoria estaria mais de acordo com o Estado Democrático de Direito, principalmente por haver a interação entre as esferas política, moral e jurídica. Cabe ressaltar, como destaque do PósPositivismo, a busca pela conciliação entre dois importantes princípios, quais sejam: a segurança jurídica e a Justiça. Esta última, considerada como o fim maior do Direito, deve ser alcançada com base em um sistema aberto, e como já dito anteriormente, em consonância com valores éticos e morais, e legitimada, em parte, por elementos supralegais. Já a segurança jurídica, por sua vez, é alcançada através da objetivação, pela máxima da proporcionalidade, da técnica da ponderação, que deve ser conduzida por um discurso racional, guiado pela Teoria da Argumentação.

Como corolário do pensamento pós-positivista, há a influência de determinadas particularidades como a nova dogmática da interpretação constitucional, a expansão da jurisdição constitucional e a força normativa da Constituição. Esta última, inclusive, foi ressaltada na obra de Hesse (2009).

De acordo com Alexy (2008), o ponto decisivo de distinção entre regras e princípios é que os princípios são normas baseadas na ponderação, na verificação jurídica e factual que se apresenta. Sendo assim, são normas de otimização, ao passo que as regras são normas que sempre são satisfeitas ou não satisfeitas ${ }^{1}$.

Com relação à colisão de princípios, isto é, conflitos envolvendo princípios diversos ou contraditórios, não há que se falar em revogação ou derrogação dos mesmos, pois não há precedência absoluta de um em relação ao outro. Há o sopesamento e avaliação para se aferir qual deles tem prioridade sobre o outro, diante de um caso concreto. Um princípio que prevaleceu diante de um caso concreto em questão pode não prevalecer em outra situação diversa.

A máxima da proporcionalidade ${ }^{2}$, dentro deste enredo, destaca-se como instrumento solucionador de conflitos entre princípios. Decompõe-se em três submáximas: a da adequação, a da necessidade e a da proporcionalidade em sentido estrito. A adequação como submáxima impõe que a medida adotada deve ser apta à consecução ou, pelo menos, à fomentação do objetivo pretendido. É a análise da existência de uma relação adequada entre meio e fim. A necessidade ou exigibilidade, por sua vez, é caracterizada pela adoção do meio menos gravoso e mais eficiente que visa alcançar determinado fim, ou seja, aquele meio que restrinja ao mínimo o direito fundamental que seria atingido em determinado caso (MENDES, 2001). Em última análise, porém não menos importante, caso persista o conflito, chega-se ao terceiro nível de exame, a submáxima da proporcionalidade em sentido estrito. Esta é caracterizada pela realização de um diagnóstico da relação custo-benefício, envolvendo a ideia de relação harmônica entre duas grandezas, entre dois princípios conflitantes. Canotilho (1995, p. 617) afirma que, mesmo em caso de uma lei ser adequada e necessária, se a mesma for restritiva, pode ela ser declarada inconstitucional, em

\footnotetext{
1 Nas palavras de Alexy (2008, p. 103-104): “Uma primeira característica importante que decorre do que foi dito até agora é o distinto caráter prima facie das regras e dos princípios. Princípios exigem que algo seja realizado na maior medida possível dentro das possibilidades jurídicas e fáticas existentes. Nesse sentido, eles não contêm um mandamento definitivo, mas apenas prima facie. Da relevância de um princípio em um determinado caso não decorre que o resultado seja aquilo que o princípio exige para esse caso. Princípios representam razões que podem ser afastadas por razões antagônicas. A forma pela qual deve ser determinada a relação entre razão e contra-razão não é algo determinado pelo próprio princípio. Os princípios, portanto, não dispõem da extensão de seu conteúdo em face dos princípios colidentes e das possibilidades fáticas. O caso das regras é totalmente diverso. Como as regras exigem que seja feito exatamente aquilo que elas ordenam, elas têm uma determinação da extensão de seu conteúdo no âmbito das possibilidades jurídicas e fáticas. Essa determinação pode falhar diante de impossibilidades jurídicas e fáticas; mas, se isso não ocorrer, então, vale definitivamente aquilo que a regra prescreve".
}

2 De acordo com Silva (2002), embora a terminologia "princípio da proporcionalidade" seja aceita por parte da doutrina e da jurisprudência, a mesma pode ser considerada errônea, principalmente quando adotado o conceito de princípio jurídico em contraposição ao conceito de regra jurídica, baseada na teoria de Alexy (2008), já abordada no presente trabalho. "Não é possível, todavia, fechar os olhos diante da prática jurídica brasileira. Quando se fala em princípio da proporcionalidade, o termo "princípio" pretende conferir a importância devida ao conceito, isto é, à exigência de proporcionalidade. Em vista disso, e em vista da própria plurivocidade do termo "princípio", não há como esperar que tal termo seja usado somente como contraposto a regra jurídica" (SILVA, 2002). Dessa forma, mais adequado seria a utilização do termo "regra da proporcionalidade" ou "máxima da proporcionalidade". 
caso de adoção de cargas coercitivas de direitos, liberdades e garantias desmedidas, excessivas ou desproporcionadas no tocante aos resultados possivelmente obtidos.

A solução para a colisão entre princípios far-se-á importante ao serem analisados os princípios da publicidade e da legalidade, encontrados no caput do artigo 37 da Constituição (BRASIL, 1988) este último atualmente conhecido como regra da juridicidade ${ }^{4}$, por ser um comando de observância do Direito como um todo, com ênfase nos direitos fundamentais e no regime democrático. Os princípios em questão serão relacionados no decorrer do estudo, ao ser abordado tópicos referentes ao edital do concurso público, requisitos admissionais e leis relacionadas a concursos públicos.

O conflito entre regras, por sua vez, dar-se-á no campo da validade e será destrinchado em quatro critérios, segundo ensinamento de Alexy (2008): através da inclusão de uma cláusula de exceção, do critério cronológico, do critério hierárquico e do critério da especialidade (ALEXY, 2008).

A inclusão de uma "cláusula de exceção" em uma das regras visa eliminar o conflito, nos casos em que uma das regras não for declarada inválida. Alexy (2008, p. 92) exemplifica da seguinte maneira:

Um exemplo para um conflito entre regras que pode ser resolvido por meio da introdução de uma cláusula de exceção é aquele entre a proibição de sair da sala de aula antes que o sinal toque e o dever de deixar a sala se soar o alarme de incêndio. Se o sinal ainda não tiver sido tocado, mas o alarme de incêndio tiver soado, essas regras conduzem a juízos concretos de dever-ser contraditórios entre si. Esse conflito deve ser solucionado por meio da inclusão, na primeira regra, de uma cláusula de exceção para o caso do alarme de incêndio.

O critério cronológico (lex posterior derrogat legi priori) mostra-se moldado para os casos de antinomias de normas de mesmo nível hierárquico. Trata-se da prevalência da norma posterior, em caso de antinomia entre duas normas criadas ou vigoradas em dois momentos temporais distintos.

O critério hierárquico (lex superior derrogat legi inferiori) consiste na precedência da norma hierarquicamente superior, em caso de normas de diferentes níveis no ordenamento jurídico. Um exemplo seria um conflito entre dispositivos constitucionais (hierarquicamente superiores) e leis ordinárias (hierarquicamente inferiores).

O critério da especialidade (lex specialis derrogat legi generali) ou da especificidade, no que lhe diz respeito, resulta na supremacia relativa a uma antinomia de normas mais específicas ao caso em questão. No caso de duas normas incoerentes uma com a outra, ao ser verificado a disposição sobre o objeto conflituoso, uma delas possui caráter mais específico, especial, em oposição ao caráter mais genérico da outra.

Cabe ressaltar também o uso das "cláusulas de exceção", que se encaixam no critério supracitado, o da especialidade. Na Teoria dos Princípios (ALEXY, 2008) as "cláusulas de exceção" delimitam a incidência normativa, em um conflito de regras aparente.

A definição da solução entre o conflito de regras será importante no decorrer deste estudo ao ser analisado os "princípios" da moralidade, eficiência e impessoalidade, dispostos no caput do

3 Art. 37 da Constituição (BRASIL,1988): “A administração pública direta e indireta de qualquer dos Poderes da União, dos Estados, do Distrito Federal e dos Municípios obedecerá aos princípios de legalidade, impessoalidade, moralidade, publicidade e eficiência [...]".

4 De acordo com Melquíades Duarte (2012), a regra da juridicidade seria o agir público adequado com todo ordenamento jurídico, ou seja, com a Constituição (BRASIL, 1988), leis, resoluções, decretos, dentre outros. A regra da juridicidade vai além da legalidade, pois vincula a atividade estatal ao conjunto de princípios e regras e valoriza a realização dos direitos do homem sobre a mera aplicação da lei. Desta forma, o princípio da legalidade, disposto no artigo 37 da Constituição (BRASIL, 1988) deve ser entendido no presente estudo como regra da juridicidade. 
artigo 37 da Constituição (BRASIL, 1988). Tais princípios serão tratados como regras ${ }^{5}$ segundo a definição de Alexy (2008), pois exigem exatamente aquilo que ordenam, não comportando sopesamentos. O concurso público em si será analisado detalhadamente no que tange aos princípios e regras basilares do instituto.

O objetivo principal do presente estudo, dentro do contexto teórico em que o mesmo se baseia, é analisar a desclassificação de candidato aprovado em concurso público baseada em limitações impostas por exames médicos admissionais. Tais exames têm a função de atestar a saúde mental e/ou física do candidato, bem como verificar a possibilidade de o mesmo exercer com qualidade e segurança, para ele e para o Estado, o cargo ou emprego público a que se pretende. $\mathrm{O}$ que será objeto de exame é exatamente essa questão: até que ponto será legítimo exigir a aptidão física ou psicológica do candidato aprovado em concurso público?

O princípio da motivação dos atos administrativos ${ }^{6}$ também será tratado como regra pela definição de Alexy (2008). Tal regra é elemento essencial em um processo (ou procedimento, como entende parte da doutrina) administrativo, pois a não observância da motivação pode acarretar a nulidade do ato. Assim define Di Pietro (2008, p. 77):

O princípio da motivação exige que a Administração Pública indique os fundamentos de fato e de direito de suas decisões. Ele está consagrado pela doutrina e pela jurisprudência, não havendo mais espaço para as velhas doutrinas que discutiam se a sua obrigatoriedade alcançava só os atos vinculados ou só os atos discricionários, ou se estava presente em ambas as categorias. A sua obrigatoriedade se justifica em qualquer tipo de ato, porque se trata de formalidade necessária para permitir o controle de legalidade dos atos administrativos.

A regra da motivação é importante para o estudo a ser apresentado, pois ao tratar da questão da exibilidade dos exames médicos, será demonstrado que tais exames devem guardar correspondência com o cargo a que se pretende. Os exames médicos devem ter a função de qualificar o candidato como apto ou não apto exclusivamente no que tange às funções que serão desempenhadas pelo mesmo, não podendo abarcar critérios desmotivados. Deverá também a desclassificação de candidato aprovado em concurso público ser motivada, sob pena de nulidade deste ato administrativo.

A Constituição (BRASIL, 1988) terá papel imprescindível no desenvolvimento deste trabalho, pois o Instituto do Concurso Público é consequência da evolução histórica constitucional, dentro de um Estado Democrático de Direito. Todos os questionamentos serão respondidos apoiados na Constituição (BRASIL, 1988), no Decreto $n^{0} 6.944$ (BRASIL, 2009) ${ }^{7}$, que dispõe sobre normas gerais relativas a concursos públicos e na Lei ${ }^{\circ} 8.112$ (BRASIL, 1990), esta última referente ao Estatuto dos Servidores Públicos Federais.

\section{BREVE ANÁLISE ACERCA DO INSTITUTO DO CONCURSO PÚBLICO}

\subsection{Contexto histórico}

\footnotetext{
5 Conforme leciona Melquíades Duarte (2012), as regras são prescrições definitivas e em caso de validez devem ser implementadas integralmente, a não ser que possuam cláusulas de exceção. "Ao oposto dos princípios, as regras destinam-se à regência de situações mais concretas e consistem, não raro, em densificação do conteúdo normativo de princípios, dos quais extraem sua racionalidade.”.

6 No presente trabalho, considera-se como ato administrativo toda ação ou omissão, com ou sem conteúdo decisório, praticadas por agente no exercício de função administrativa.

7 Decreto $\mathrm{n}^{\circ}$ 6.944, de 21 de agosto de 2009. Estabelece medidas organizacionais para o aprimoramento da administração pública federal direta, autárquica e fundacional, dispõe sobre normas gerais relativas a concursos públicos, organiza sob a forma de sistema as atividades de organização e inovação institucional do Governo Federal, e dá outras providências.
} 
O Concurso Público tem suas raízes históricas no século XIX, quando houve uma reconstrução da Administração Pública, através de uma reação contra a arbitrariedade e mercantilismo como meio de acesso aos cargos públicos. Essa reação sinalizava que o exercício de cargos e funções públicas não poderia advir de privilégios, e desenvolveu-se na França, a partir da resistência de Napoleão Bonaparte contra seus opositores, que eram beneficiados por outros sistemas (CRETELLA JÚNIOR, 1994).

Durante o Brasil Império, entre os anos 1822 a 1889, cabia ao Imperador o poder de delegação de funções públicas. Esta modalidade de provimento de cargos públicos era baseada na confiança, pois o Imperador tinha livre arbítrio para admitir ou exonerar funcionários públicos quando quisesse (MELLO, 1990).

Em 1889, com a Proclamação da República, manteve-se a modalidade calcada na confiança, mesmo após a promulgação da nova Constituição, dois anos depois. Em 1934, assistiu-se a um importante fato, o surgimento do concurso público no ordenamento jurídico brasileiro. Tal fato é decorrência da Revolução Constitucionalista que levou Getúlio Vargas a realizar o Golpe do Estado Novo, e ensejou a promulgação da Constituição da República dos Estados Unidos do Brasil (MELLO, 1990).

A Constituição (BRASIL, 1934) deste período, embora representasse um passo inicial da adoção do instituto conhecido atualmente, era dotada de contrariedades e não abarcava os empregos públicos.

Somente em 1967, através da sexta Constituição do Brasil, foi validada a obrigatoriedade do concurso público como modalidade de ingresso para todos os cargos públicos, exceto para os cargos eletivos e em comissão (de confiança) (MELLO, 1990).

De todo o exposto, percebe-se que o acesso a cargos públicos nem sempre foi pautado na impessoalidade e igualdade como principais características, mas em critérios puramente particulares, que beneficiavam pessoas influentes ou semelhantes. Porém, com a evolução das Constituições do Brasil, em especial a Constituição (BRASIL, 1988), houve uma ampliação dos direitos e garantias fundamentais e o instituto em tela avançou para o que se conhece atualmente.

\subsection{O conceito de concurso público}

Inicialmente, cumpre destacar que o concurso público em questão refere-se ao processo seletivo de pessoal para ingresso na Administração Pública, diverso daquele disposto no inciso IV do artigo 22 da Lei $n^{0} 8.666$ (BRASIL, 1993), relativo a uma modalidade de licitação. O concurso público encontra-se disciplinado no inciso II do artigo 37 da Constituição (BRASIL, 1988), nos seguintes termos:

\section{Art. 37. [...] omissis}

II. A investidura em cargo ou emprego público depende de aprovação prévia em concurso público de provas ou de provas e títulos, de acordo com a natureza e a complexidade do cargo ou emprego, na forma prevista em lei, ressalvadas as nomeações para cargo em comissão declarado em lei de livre nomeação e exoneração.

Importante tecer alguns comentários a respeito do inciso supracitado. Cargo e emprego público possuem suas particularidades. Cargo público possui caráter institucional, estatutário, ao passo que emprego público possui caráter contratual, trabalhista. Ambos só podem ser criados por lei e são de iniciativa privativa do Presidente da República, segundo a Constituição (BRASIL, 1988). Cargos Públicos são também, segundo Bandeira de Mello (2002), estruturas simples e indivisíveis expressadas por um agente, determinadas por um número certo, com denominação 
própria, retribuídas por pessoas jurídicas de Direito Público e são regidos pela Lei $\mathrm{n}^{\mathrm{o}} 8.112$ (BRASIL, 1990) ${ }^{8}$. Emprego público, por sua vez, é caracterizado pelo exercício da função pública através de vínculo contratual, regulamentado pelo Decreto no 5.452 (BRASIL, 1943), que aprova a Consolidação das Leis do Trabalho.

Os cargos em comissão são de caráter transitório, em que seus titulares são nomeados em função da relação de confiança que existe entre eles e a autoridade responsável pela nomeação. Nas palavras de Bandeira de Mello (2002, p. 269):

Os cargos de provimento em comissão (cujo provimento dispensa concurso público) são aqueles vocacionados para serem ocupados em caráter transitório por pessoa de confiança da autoridade competente para preenchê-los, a qual também pode exonerar ad nutum, isto é, livremente, quem os esteja titularizando.

A ressalva feita com relação aos cargos em comissão declarados em lei de livre nomeação e exoneração é atribuída aos casos em que tal cargo ocupa um espaço na estrutura, no quadro funcional da Administração (reservado o limite mínimo exigido por lei), pois se escolhe uma pessoa qualquer, da confiança da autoridade que nomeia (não necessariamente um servidor público), e atribui-se uma série de responsabilidades inerentes ao cargo. Tal nomeação difere-se do disposto no inciso $\mathrm{V}$ do mesmo artigo ${ }^{9}$, referente às funções de confiança, sendo estas exercidas por servidores efetivos, já pertencentes ao quadro estrutural da Administração Pública.

Existem ainda, outras espécies de vínculos das pessoas físicas com o Estado, como os referentes aos agentes políticos; aos servidores temporários, aos contratados em virtude da necessidade temporária e excepcional do interesse público; aos particulares que atuam em colaboração com o poder público, isto é, pessoas físicas que atuam sem vínculo de trabalho com a Administração Pública; aos particulares por delegação (agentes delegados); aos agentes necessários (voluntários); aos agentes credenciados; aos militares (CARDOSO; PEDRO, 2011).

A obrigatoriedade de concurso para ingresso no serviço público faz-se evidente no inciso II do artigo 37, somado ao caput do mesmo artigo da Constituição (BRASIL, 1988), no que diz respeito aos cargos e empregos públicos, excetuando-se os cargos eletivos a serem providos mediante sufrágio.

De acordo com Alexy (2008), a qualificação de uma norma como regra ou princípio é tarefa do intérprete. Exercendo esta prerrogativa, constata-se que a exigência de concurso para o acesso aos cargos e empregos efetivos é veiculada por regra constitucional, por tratar-se de um comando absoluto, que não comporta restrições.

Desta forma, será inconstitucional qualquer processo seletivo que não respeite a regra do artigo mencionado (a necessidade de aprovação prévia em concurso público de provas ou provas e títulos). Regra, como já definido anteriormente, contém um mandamento definitivo, exige exatamente aquilo que ordena, tem uma determinada extensão de seu conteúdo no âmbito das possibilidades jurídicas e fáticas (ALEXY, 2008).

Com relação aos "princípios" dispostos no referido artigo, faz-se necessário analisá-los de uma forma mais detida. Princípio, segundo Alexy (2008), é um comando de otimização, pois possui um caráter prima facie diverso daquele das regras. Segundo o autor, princípios não contêm um mandamento definitivo, isto é, podem ser afastados um em razão do outro em um eventual conflito e sua aplicação dependerá das possibilidades fáticas.

8 Art. $3^{\circ}$ da Lei no 8.112 (BRASIL, 1990): “Cargo público é o conjunto de atribuições e responsabilidades previstas na estrutura organizacional que devem ser cometidas a um servidor".

9 Inciso V do art. 37 da Constituição (BRASIL, 1988): "as funções de confiança, exercidas exclusivamente por servidores ocupantes de cargo efetivo, e os cargos em comissão, a serem preenchidos por servidores de carreira nos casos, condições e percentuais mínimos previstos em lei, destinam-se apenas às atribuições de direção, chefia e assessoramento;". 
No entanto, as regras (juridicidade, moralidade, eficiência e impessoalidade) mencionadas no artigo 37 da Constituição (BRASIL, 1988) devem ser analisadas separadamente, de forma singular, pois cada uma comporta uma interpretação diferente no que tange ao instituto do concurso público.

Todo concurso público ${ }^{10}$ deve ser impessoal, moral e eficiente, viabilizando critérios capazes de selecionar bons candidatos e observando, portanto, os dizeres do edital. Segundo o inciso III do artigo 37 da Constituição (BRASIL, 1988), o prazo de validade do concurso público será de até dois anos, prorrogável uma vez, por igual período. A observância do prazo torna-se importante no que tange à eficiência do concurso, pois visa garantir a convocação ${ }^{11}$ dos candidatos aprovados dentro do número de vagas dispostas no edital, baseando-se em um critério temporal razoável. Cabe ressaltar também que, em decorrência da obrigatoriedade de realizar concursos, as contratações discricionárias foram afastadas (SPITZCOVSKY, 2004). As regras da impessoalidade, moralidade e eficiência, se não seguidas integralmente, eivam de vício o ato administrativo, tornando-o inconstitucional. Devem então ser guardadas de forma incontestável, com vistas a garantir a lisura do procedimento.

Deve também o concurso público ser transparente, no sentido de que representa os interesses tutelados pelo Poder Público que objetivam o bem da coletividade (SPITZCOVSKY, 2004). Todos os atos realizados no edital devem ser publicizados, a fim de assegurar a ampla concorrência e resguardar os direitos dos candidatos, que em alguns casos acabam sendo prejudicados quando da omissão de algum ato ${ }^{12}$.

10 Cabe aqui um posicionamento, referente a uma questão presente no contexto social atual. No tocante às características do concurso público, de acordo com Meirelles (1999, p. 387), é o meio considerado mais justo e igualitário de ingresso no setor público, no qual o candidato melhor condicionado e qualificado obtém acesso aos cargos, empregos e funções. Entretanto, essa concepção, baseada na meritocracia, apresenta impasses, pois em uma sociedade em que riqueza, renda e classe social são determinadas através da competição e do merecimento, gera-se um efeito reverso ao que se pretende, produz-se a desigualdade (BARBOSA, 1999). A "cultura da meritocracia", representada por uma dimensão negativa, que seria uma interpretação da meritocracia baseada somente no esforço pessoal, sem influência de privilégios hereditários ou corporativos, na verdade demonstra-se ineficiente, pois é sabido que vários outros fatores possibilitaram a determinado indivíduo a ter melhores condições que outro, e não somente seu esforço pessoal. Em uma sociedade tão diversificada, fica difícil avaliar o mérito individual (BARBOSA, 1999), pois os sujeitos partem de posições iniciais diferentes. O concurso público, tal como é concebido atualmente, pode ser considerado como uma verdadeira "máquina de injustiça social", pois apesar de seus critérios serem pautados na igualdade de oportunidades, sabe-se que nem todos possuem as mesmas condições para se preparar; enquanto uns podem se dedicar aos estudos e pagar cursos preparatórios, outros precisam trabalhar e estudar no tempo livre. A própria educação infelizmente não é um instrumento que garante acesso igualitário às posições sociais, pois o acesso a ela é variado.

11 Existem polêmicas em torno da ausência de discricionariedade na convocação e do direito subjetivo à nomeação dentro do número de vagas do edital. A Administração Pública deve agir de boa-fé e, utilizando-se do juízo de conveniência e oportunidade, prover as vagas que, quando da divulgação do edital, afirmou existirem. Assim entende o Superior Tribunal de Justiça: CONCURSO PÚBLICO. NOMEAÇÃO. ATO VINCULADO. É dever da Administração Pública nomear os candidatos aprovados para as vagas oferecidas no edital do concurso. Com a veiculação em edital de que a Administração necessita prover determinado número de vagas, a nomeação e posse, que seriam, a princípio, atos discricionários, tornam-se vinculados, gerando, em consequência, direito subjetivo para o candidato aprovado dentro do número de vagas previsto no edital. Precedentes citados: RMS 15.420-PR; RMS 15.345-GO, DJ 24/4/2007, e RMS 15.034-RS, DJ 29/3/2004. (RMS 19.478-SP, Rel. Min. Nilson Naves, julgado em 6/5/2008). No que tange à discricionariedade na convocação, a regra da impessoalidade deve ser imposta, não podendo ser desrespeitada. A Administração Pública, voltada para o interesse público, não pode se valer de critérios discricionários ao convocar candidatos aprovados, devendo respeitar a ordem de classificação, com base nas regras do edital. Qualquer favorecimento de um candidato em detrimento de outro é vedado.

12 APELAČÃO CÍVEL-MANDADO DE SEGURANÇA-CONCURSO PÚBLICO-CANDIDATA QUENÃOFOI CLASSIFICADA NA PRIMEIRA FASE DO CONCURSO PÚBLICO PARA SOLDADO DA POLICIA MILITAR E DEIXOU DE ACOMPANHAR AS SUBSEQUENTES PUBLICAÇÕES - CHAMAMENTO COMPLEMENTAR - AUSÊNCIA DE PREVISÃO EDITALÍCIA - VIOLAČ̃̃O A̧O PRINCÍPIO DA PUBLICIDADE E DA VINCULAÇÃO AO EDITAL - DEVIDA PARTICIPAÇÃO DA RECORRIDA NA ENTREVISTA PARA VERIFICAÇÃO DE AFRODESCENDÊNCIA - RECURŞO DESPROVIDO. A convocação de candidatos não classificados na primeira fase, de certame do qual participa em conduta não prevista no Edital, deve ser realizada com eficaz publicidade. O mero anúncio em site da internet e no Diário Oficial não basta, impondo-se a anulação do ato que desclassificou a candidata por não comparecimento na entrevista para verificação de afro descendência. (TJ-PR - AC: 5954507 PR 0595450-7, Relator: Regina Afonso Portes Data de Julgamento: 28/06/2010, 4ª Câmara Cível, Data de Publicação: DJ: 433). 
No entanto, o princípio da publicidade merece ser tratado com certa cautela. A transparência, no que se refere aos objetos dispostos pelo edital, bem como todos os seus atos, deve ser exercida em sua totalidade. Porém, no que tange a elementos como a privacidade, há que se ter sigilo. A própria lei ${ }^{13}$ diz que o candidato reprovado em exame psicológico deve ter seu nome apenas associado com o resultado "apto/inapto", não sendo detalhado o motivo pelo qual gerou o resultado. Esta análise aponta para a classificação do princípio da publicidade como, segundo a Teoria dos Direitos Fundamentais (ALEXY, 2008), um princípio, isto é, um comando de otimização, que será analisado conforme as possibilidades jurídicas e fáticas do caso concreto, sujeito a sopesamentos (ALEXY, 2008).

Por fim, o "princípio" da legalidade, cujo conteúdo jurídico situa-se na regra da juridicidade (MELQUÍADES DUARTE, 2012), implica o dever da Administração Pública de realizar suas ações sempre pautadas no Direito, no ordenamento jurídico como um todo. Neste caso, impõe também a observância das condições dispostas no edital (se estão de acordo com a Constituição, respeitam os direitos e garantias dos cidadãos e se o procedimento, da abertura ao encerramento do concurso, não apresenta algum erro, etc).

\section{O EXAME MÉDICO ADMISSIONAL}

O exame médico admissional é uma das etapas finais do concurso para ingresso no setor público. Está previsto em lei, pois somente esta pode veicular exigências para o provimento de cargo público, sendo precedente ao edital do concurso público. Deve-se observar que, em muitos estatutos de servidores públicos, existe a determinação de avaliação médica e/ou mental dos candidatos aprovados, para que estes possam tomar posse. Assim prevê, por exemplo, o artigo 14 da Lei no 8.112 (BRASIL, 1990): “A posse em cargo público dependerá de prévia inspeção médica oficial. Parágrafo único. Só poderá ser empossado aquele que for julgado apto física e mentalmente para o exercício do cargo".

A exigência legal, por ter característica excludente enquanto critério de avaliação, deve obedecer à máxima da proporcionalidade. Tal máxima, como mencionado anteriormente, decompõe-se em três submáximas (adequação, necessidade e proporcionalidade em sentido estrito), que deverão ser observadas na elaboração da lista de exames médicos.

Interessante ressaltar o fato de que os exames médicos devem ser especificados de forma incisiva no edital do concurso público. Tal tema inclusive já foi alvo do Tribunal Superior do Trabalho, ao julgar o agravo de instrumento em recurso de revista $\mathrm{n}^{0}$ 14162-18.2010.5.04.0000 (BRASIL, 2011). No agravo em questão, o candidato teria sido desclassificado com base em laudo de ressonância magnética, que apontou "mínima protrusão posterior" da coluna cervical e "pequena hérnia póstero-lateral esquerda". No entanto, o edital previa apenas a exigência de boa saúde física e mental, sem a especificação das condições que seriam objeto de eliminação. Seria apenas uma análise ampla, pois “boa saúde física e mental” é um critério muito genérico, não existindo fundamentos diretamente relacionados com as funções que seriam desempenhadas. Houve um exercício desarrazoado por parte do agente público que solicitou o exame, gerando insegurança jurídica. No agravo supracitado, ao analisar o caso, foi reconhecida a ilicitude da eliminação, sob a tese de que o edital não guardava previsão relacionada à justificativa do ato de eliminação. Dessa forma, o ideal é que a Administração Pública especifique no edital os parâmetros que deverão compor o conceito de boa saúde previsto em lei, bem como os exames médicos e procedimentos para comprovação, e, por óbvio, que tais parâmetros sejam pautados pela máxima da proporcionalidade.

O exame médico admissional tem caráter eliminatório, pois possui como objetivo principal

13 Art. 14-A do Decreto n 6.944 (BRASIL, 2009): “O resultado final da avaliação psicológica do candidato será divulgado, exclusivamente, como "apto" ou "inapto"”. 
avaliar as capacidades físicas e mentais dos candidatos, e, de maneira ampla, devem ser consideradas condições mínimas para que se tenha uma boa saúde. O que se questiona não é a importância de toda e qualquer perícia médica, pois esta, quando proporcional, exerce papel imprescindível na aferição da capacidade do candidato aprovado. Discute-se a possibilidade de que sejam solicitados exames abusivos, que, muitas vezes, não guardam correspondência com a função do cargo público a cujo provimento destina-se a salvaguardar. O exame médico só é legítimo se for para averiguar a satisfatoriedade de exigência legal, se esta for proporcional e se for especificada no edital.

Um concurso público para provimento de cargos de piloto de aviação, por exemplo, deve conter requisitos pautados especificamente no que tange à função inerente ao cargo. Deve focar na capacidade visual e psicomotora do candidato, observando se o mesmo possui plenas condições de pilotar um avião de forma segura, a fim de proteger tanto o profissional quanto as pessoas que irão usufruir daquele serviço. É adequado o exame de vista para o cargo referido, pois é apto à obtenção do resultado pretendido, qual seja, a acuidade visual, essencial para um piloto. É necessário tal exame, pois pode ser considerado o meio menos gravoso de aferição da característica em questão. É proporcional em sentido estrito, pois, diante de uma relação de custo-benefício, o exame oftalmológico é considerado um exame simples, de fácil acesso e que atinge o objetivo a que se propõe (viabilizar a segurança do profissional e dos passageiros).

É importante ressaltar que, até mesmo para o concurso supramencionado, há certo grau de flexibilização, ainda que mínimo. De acordo com as instruções técnicas de inspeção de saúde na aeronáutica ${ }^{14}$, é permitido grau mínimo de hipermetropia e de astigmatismo, desde que não atrapalhe a visão.

Em contrapartida, um critério de seleção baseado, por exemplo, na presença de cicatrizes na pele do candidato não seria razoável, uma vez que em nada interferem nas funções que serão desempenhadas pelo piloto, sendo o serviço prestado da mesma forma ${ }^{15}$. Tal excludente não estaria de acordo com a máxima da proporcionalidade.

Nem sempre, porém, os requisitos médicos dispostos pelo edital são proporcionais ${ }^{16}$. Tal assertiva fica evidente ao ser analisada a apelação n ${ }^{\circ} 00641452220108260000$ do Tribunal de Justiça de São Paulo (SÃO PAULO, 2013) ${ }^{17}$. Trata-se de um mandado de segurança impetrado por um

14 PORTARIA DIRSA N79/SECSDTEC, de 23 de maio de 2012. Aprova a Reedição da Instrução que trata das Inspeções de Saúde na Aeronáutica. (BRASIL, 2012).

15 De acordo com o item 4.1.2.9.1 da Portaria DIRSA No79/SECSDTEC, referente às instruções de inspeções de saúde na Aeronáutica, observa-se o seguinte: "Inexistência de cicatriz que, por sua natureza ou localização, possa, em face do uso de equipamento militar e do exercício das atividades militares, vir a motivar qualquer perturbação funcional ou ulcerar-se". Dessa forma, é permitido qualquer cicatriz no corpo do candidato, desde que a mesma não cause nenhuma limitação no desempenho das funções.

16 Cabe aqui uma ressalva no que diz respeito ao candidato possuir tatuagem. O Supremo Tribunal Federal decidiu recentemente sobre a questão, ao julgar um recurso de um candidato que foi desclassificado em um concurso para bombeiro militar do Estado de São Paulo. De acordo com edital do certame, nenhum candidato que tivesse tatuagem que atentasse contra "a moral e os bons costumes", que cobrisse partes inteiras do corpo, seria admitido. Ora, tal restrição, além de genérica, é discriminatória e não guarda nenhuma relação com a função que seria desempenhada pelo profissional. Ficou decidido no recurso citado que tal exigência não poderia ser permitida, só podendo haver restrição em caso de o conteúdo da tatuagem violar "valores constitucionais", como por exemplo, incitação à violência, grave ameaça, preconceitos raciais, entre outros. Essa decisão deverá ser seguida pelas demais instâncias judiciais ao analisarem casos semelhantes. Enfim, a decisão a respeito da tatuagem deverá ser analisada no caso concreto, pautada pela máxima da proporcionalidade, e não apenas de acordo com um critério genérico previsto no edital do concurso. Percebe-se na ementa de um caso semelhante, a título de exemplo: "POLICIAL MILITAR. CONCURSO PÚBLICO DE INGRESSO NA CARREIRA. TATUAGEM. CONCURSO PÚBLICO. REPROVAÇÃO EM EXAME MÉDICO. Exclusão do candidato na etapa de exames médicos. Inaptidão que decorre da tatuagem. Não reconhecida. Tatuagem não expressa incompatibilidade com a função. Inocorrência de violação ao edital. Razoabilidade. A tatuagem não é visível com uso do uniforme. Inabilitação afastada. Precedentes jurisprudenciais. RECURSO PROVIDO”. (TJSP-APL: 00177726020138260053 SP 0017772-60.2013.8.26.0053, Relator: José Maria Câmara Junior, Data de Julgamento: 27/08/2014, $9^{a}$ Câmara de Direito Público, Data de Publicação: 27/08/2014)

17 MANDADO DE SEGURANÇA CONCURSO PÚBLICO SOLDADO DA POLÍCIA MILITAR CANDIDATO REPROVADO NO EXAME MÉDICO-ODONTOLÓGICO POR POSSUIR MORDIDA CRUZADA ABUSO DA ADMINISTRAÇÃO CARACTERIZADO ORDEM CONCEDIDA SENTENÇA CONFIRMADA. (TJ-SP APL: 00641452220108260000 SP 0064145-22.2010.8.26.0000, Relator: Ricardo Feitosa. Data de Julgamento: 05/08/2013, $4^{a}$ Câmara de Direito Público, Data de Publicação: 09/08/2013). 
candidato reprovado no exame médico-odontológico por possuir mordida cruzada, característica que estaria em desacordo com os critérios dispostos no edital do certame. No entanto, o fato de possuir mordida cruzada de nada interfere nas funções que seriam desempenhadas no cargo de soldado da Polícia Militar. O exame em questão mostra-se totalmente em desacordo com a máxima da proporcionalidade. Não é adequado, pois, não se presta a um fim pertinente ao exercício da função, constituindo inclusive discriminação, segundo o inciso IV do artigo $3^{\circ}$ da Constituição (BRASIL, 1988) $)^{18}$ e restrição a direito fundamental, qual seja, o direito de igualdade.

Outro caso que corrobora o ponto de vista apresentado neste trabalho refere-se a um concurso público para o provimento de empregos de carteiro. $\mathrm{O}$ candidato conseguiu obter reformação da sentença após provar que as anormalidades encontradas no exame não o impediriam de exercer normalmente as atribuições do cargo em questão ${ }^{19}$. Na situação em tela, o candidato teria sido desclassificado por ter sido reprovado nos testes de aptidão física realizados pela banca do concurso, nos quais ficaram evidenciadas anomalias não incapacitantes na coluna e no joelho. Porém, tais anomalias não seriam suficientes para impedi-lo de exercer com excelência as funções atribuídas ao cargo almejado, não havendo razão alguma para que o mesmo fosse excluído do certame. O exame médico, como já explicado, tem a função de averiguar se o candidato possui de fato condições reais de trabalho, e não apenas de caracterizar um formalismo descabido. É preciso ter a certeza de que o candidato é o melhor qualificado entre os demais que participaram do processo seletivo.

Ainda sob a égide da máxima da proporcionalidade, bem como das regras dispostas pelo artigo 37 da Constituição (BRASIL, 1988), referentes ao concurso público, cabe exemplificar outro caso em que houve a inobservância do ponto de vista apresentado até aqui. Em um mandado de segurança impetrado por candidato desclassificado em razão da altura, percebe-se claramente um formalismo excessivo e descabido. A diferença mínima de altura (um centímetro) de nada atrapalharia o candidato ao cargo que ocuparia, qual seja o de soldado da Polícia Militar do Maranhão. Insta salientar que o mesmo, ao ser desclassificado no exame médico em questão (medição antropométrica), já teria passado por outros exames, como os de aptidão física e psicotécnico. Assim, o requisito objetivo (altura mínima de 1,65 metros) não deve ser interpretado categoricamente, mas mitigado, de tal forma que um centímetro em nada atrapalharia o candidato no desempenho de sua função. Foi o que ficou decidido de modo acertado no conteúdo do mandado ${ }^{20}$, pela concessão da segurança, determinando que o impetrante participasse das demais

18 Inciso IV do art. $3^{\circ}$ da Constituição (BRASIL, 1988): "promover o bem de todos, sem preconceitos de origem, raça, sexo, cor, idade e quaisquer outras formas de discriminação".

19 DIREITO ADMINISTRATIVO E CONSTITUCIONAL. CONCURSO PÚBLICO. EMPREGO DE CARTEIRO. REPROVAÇ̃̃O EM EXAME MÉDICO. ANORMALIDADE FÍSICA QUE NÃO PREJUDICA GRAVEMENTE A ATIVIDADE. INTERPRETAÇÃO FAVORÁVEL AO CANDIDATO. DIREITO À IMEDIATA CONTRATAÇÃO. SENTENÇA REFORMADA. 1. A jurisprudência da Corte vem admitindo que apesar da atividade exercida pelos carteiros, consistente na entrega de correspondências e encomendas, requerer aptidão física razoável dos agentes que pleiteiam as vagas do certame, se o candidato for considerado como habilitado pela perícia efetuada em juízo, e, não estando a patologia entre as expressamente previstas pelo edital, não há razões para que o mesmo seja impedido de assumir o emprego público. 2. Os documentos colacionados aos autos demonstram que o autor após haver sido considerado inapto para o cargo de carteiro nos testes de aptidão física ministrados pela comissão do concurso, submeteu-se a uma perícia médica judicial, que apesar de ter encontrado as mesmas anomalias na sua coluna e joelhos entendeu que não são elas suficientes para causar-lhe nenhum impedimento laboral, considerando-o apto inclusive para o exercício das funções inerentes ao emprego público de carteiro. 3. Recurso de apelação provido. (TRF-1 - AC: 39715020084013200 AM 0003971-50.2008.4.01.3200, Relator: DESEMBARGADOR FEDERAL CARLOS MOREIRA ALVES, Data de Julgamento: 08/11/2013, SEXTA TURMA, Data de Publicação: e-DJF1 p.644 de 22/11/2013).

20 ADMINISTRATIVO. MANDADO DE SEGURANÇA. COISA JULGADA. AFASTADA. CONCURSO PÚBLICO. ALTURA MÍNIMA. EXIGÊNCIA EDITALÍCIA. PRINCÍPIO DA RAZOABILIDADE E PROPORCIONALIDADE. CANDIDATO QUE FOI DESCLASSIFICADO POR APENAS 1CM (UM CENTÍMETRO) DA ALTURA MÍNIMA. SEGURANÇA CONCEDIDA. I - Inexiste óbice a propositura de nova ação com as mesmas partes, objeto e causa de pedir, desde que seja acompanhada de prova pré-constituída apta a demonstrar o alegado direito líquido e certo do impetrante. Precedente do STJ.AGrg no AGrg no MS 18692/DF. II - O entendimento do Superior Tribunal de Justiça e deste Tribunal de Justiça é no sentido de que as exigências de 
etapas do certame.

Em busca de um contraponto ao que já foi demonstrado até aqui, tem-se no agravo interno de agravo de instrumento $n^{\circ}$ 0027771-94.2013.8.19.0000 (RIO DE JANEIRO, 2013) um caso em que ficou evidenciada a correta observância do exame médico como motivo de desclassificação do candidato aprovado em concurso público. Na situação em tela, a candidata foi desclassificada no concurso para provimento do cargo de professor por ter sido reprovada na fase de exame médico, especificamente em razão de problemas vocais. O cargo de professor, como é sabido, exige do profissional o uso constante da voz, de forma que esta pode ser considerada essencial para o desempenho da função. Sem a qualidade mínima da voz, condição sine qua non para um professor, o serviço não consegue ser prestado, não atingindo o fim a que se destina.

Isto posto, percebe-se que, nesta oportunidade, houve a aplicação acertada dos critérios trabalhados neste estudo, pois foi respeitada a máxima da proporcionalidade, sendo a medida considerada adequada, pois a desclassificação guarda correta conformidade com o exercício da função, atingindo o fim destinado; necessária e exigível, pois tal medida é eficiente, não cabendo interpretação contrária e proporcional em sentido estrito, por harmonia na tomada da decisão, na correta interpretação entre os princípios conflitantes, entre o direito da candidata de se submeter ao concurso e o exercício efetivo da função. Segue trecho da decisão do agravo interno em questão:

Agravo Interno em Agravo de Instrumento. Concurso Público. Professor II do Município do Rio de Janeiro. Reprovação na fase de exame médico, em razão de alterações no aparelho fonador. Liminar indeferida. Aferição médica que se afigura regular, pois relacionada ao exercício das funções inerentes ao cargo almejado. Precedentes desta Corte. Documentos dos autos que demonstram que durante os cerca de nove meses que mediaram a realização do exame e as revisões subsequentes apresentava a autora problemas vocais que, a princípio, justificavam sua eliminação. Ausência dos requisitos do artigo 273 do CPC. Desprovimento do recurso.

Após análise do trecho supramencionado, percebe-se que no conteúdo da decisão existe também o critério temporal, pois esteve a candidata sob observação durante nove meses, interstício que perdurou da realização do exame até a referida deliberação. Durante esse lapso de tempo, ocorreram revisões com o intuito de aferir realmente a incapacidade da candidata, que restou comprovada. Enfim, o critério temporal contribuiu para o correto veredito, que mostrou-se razoável e devidamente motivado.

\section{CONCLUSÃO}

A questão levantada pelo presente estudo ficou elucidada pelo exposto nas páginas anteriores. Em um primeiro momento, abarcado pelo contexto pós-positivista, foi feita uma breve análise acerca do instituto do concurso público, passando por sua conjuntura histórica e conceituação. Observou-se que os exames médicos em geral, para que estejam dispostos no edital de determinado concurso, primeiro devem conter embasamento em lei, pois somente esta pode veicular exigências para o provimento de cargo público.

altura, idade e sexo para ingresso na carreira militar são possíveis, porém podem ser mitigadas quando o candidato (o) fica no limite da margem de $01 \mathrm{~cm}$ da altura mínima exigida. III - Ademais, a diferença de 01 (um) centímetro pode decorrer de variação entre os aparelhos de aferição de medidas, portanto, esse fato por si só não pode ser considerado para desclassificar o impetrante do concurso público, por violar o princípio da razoabilidade. Especialmente quando demonstrado que mede $1,65 \mathrm{~m}$ de altura, medida esta aferida por órgão oficial. IV - Segurança concedida. (TJ-MA MS: 0518542015 MA 0009198-86.2015.8.10.0000, Relator: JOSÉ DE RIBAMAR CASTRO. Data de Julgamento: 04/12/2015, PRIMEIRAS CÂMARAS CÍVEIS REUNIDAS, Data de Publicação: 09/12/2015). 
Criticou-se a exigência de exames que visam aferir um elemento inerente ao estado de saúde do indivíduo que não possui pertinência com as funções a serem desempenhadas por ele.

Defendeu-se que a avaliação médica deve ser orientada pela máxima da proporcionalidade, bem como pelas regras mencionadas pelo artigo 37 da Constituição (BRASIL, 1988), pelo princípio da publicidade e pelos dispositivos legais associados ao concurso público ${ }^{21}$, conferindo a esta avaliação critérios objetivos e científicos compatíveis ao exercício do cargo público pretendido.

Foi mencionado, neste estudo que, de acordo com a regra da motivação dos atos administrativos, toda desclassificação de candidato por problemas detectados no exame médico deve ser justificada, pois a ausência de fundamentação causará a nulidade do ato administrativo em questão. Afinal, tem o candidato o direito de conhecer os motivos que o desclassificaram do certame, para assim poder exercer seu direito constitucional de ampla defesa e contraditório.

Com base na regra da juridicidade, que impõe ao Poder Público a observância da lei e dos princípios do ordenamento jurídico enquanto sistema, pode-se concluir que o administrador público deve agir guiado pela proporcionalidade ao instituir as regras de um edital de um concurso público, a fim de evitar exigências desmesuradas para o exercício do cargo a ser provido. Não é razoável que, em um Estado Democrático de Direito, ainda existam limitações descabidas ou até discriminatórias, que restrinjam o direito das pessoas de participar de forma igualitária de determinados processos seletivos.

\section{REFERÊNCIAS}

ALEXY, Robert. Teoria da argumentação jurídica. 3. ed. Rio de Janeiro: Forense, 2011.

ALEXY, Robert. Teoria dos direitos fundamentais. Tradução de Virgílio Afonso da Silva. 2. ed. São Paulo: Malheiros, 2008.

BARBOSA, Lívia. Igualdade e meritocracia. 2. ed. Rio de Janeiro: Editora FGV, 1999.

BARROSO, Luís Roberto. Curso de direito constitucional contemporâneo: os conceitos fundamentais e a construção do novo modelo. 3. ed. São Paulo: Saraiva, 2011.

BRASIL. [Constituição (1934)]. Constituição da República dos Estados Unidos do Brasil. Nós, os representantes do povo brasileiro, pondo a nossa confiança em Deus, reunidos em Assembléia Nacional Constituinte para organizar um regime democrático, que assegure à Nação a unidade, a liberdade, a justiça e o bem-estar social e econômico, decretamos e promulgamos a seguinte. Disponível em: http://www.planalto.gov.br/ccivil_03/Constituicao/Constituicao34.htm. Acesso em: 18 out. 2016.

BRASIL. [Constituição (1988)]. Constituição da República Federativa do Brasil. Disponível em: <http://www.planalto.gov.br/ccivil_03/Constituicao/Constituicao.htm>. Acesso em: 18 out. 2016.

BRASIL. Decreto $\mathbf{n}^{\mathbf{0}} \mathbf{5 . 4 5 2}$, de $\mathbf{1}^{\mathbf{0}}$ de maio de 1943. Aprova a Consolidação das Leis do Trabalho. Disponível em: <https://www.planalto.gov.br/ccivil_03/Decreto-Lei/Del5452.htm>. Acesso em: 3 out. 2016.

BRASIL. Decreto $\mathbf{n}^{\mathbf{0}}$ 6.944, de 21 de agosto de 2009. Estabelece medidas organizacionais para

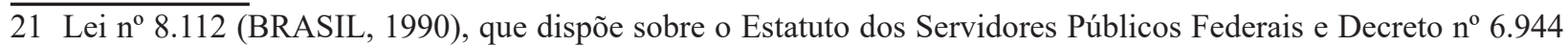
(BRASIL, 2009), relativo às normas gerais de concursos públicos. 
o aprimoramento da administração pública federal direta, autárquica e fundacional, dispõe sobre normas gerais relativas a concursos públicos, organiza sob a forma de sistema as atividades de organização e inovação institucional do Governo Federal, e dá outras providências. Disponível em: <http://www.planalto.gov.br/ccivil_03/_ato2007-2010/2009/decreto/d6944.htm>. Acesso em 03 out. 2016.

BRASIL. Lei n⿳0 8.112, de 11 de dezembro de 1990. Dispõe sobre o regime jurídico dos servidores públicos civis da União, das autarquias e das fundações públicas federais. Disponível em: $<$ http:// www.planalto.gov.br/ccivil_03/leis/L8112cons.htm>. Acesso em 03 out. 2016.

BRASIL. Lei $n^{0}$ 8.666, de 21 de junho de 1993. Regulamenta o art. 37, inciso XXI, da Constituição Federal, institui normas para licitações e contratos da Administração Pública e dá outras providências. Disponível em: <https://www.planalto.gov.br/ccivil_03/LEIS/L8666cons. htm>. Acesso em 03 out. 2016.

BRASIL. Ministério da Defesa. Comando da Aeronáutica. Diretoria de Saúde. Portaria DIRSA n79/SECSDTEC, de 23 de maio de 2012. Aprova a Reedição da Instrução que trata das Inspeções de Saúde na Aeronáutica. Disponível em: <http://www.fab.mil.br/icas/ICA_160-6_NOV_2012. pdf>. Acesso em: 1 nov. 2016.

BRASIL. Tribunal Superior do Trabalho. Agravo de instrumento em recurso de revista n'141621820105040000 14162-18.2010.5.04.0000. Agravante: Companhia Riograndense de Saneamento-CORSAN.Agravado: EniltonMoreira Goulart.Relatora:DoraMaria da Costa. Brasília, 03 de agosto de 2011. Disponível em: < http://tst.jusbrasil.com.br/jurisprudencia/20185204/agravode-instrumento-em-recurso-de-revista-airr-141621820105040000-14162-1820105040000/ inteiro-teor-104843528>. Acesso em: 7 nov. 2016.

CANOTILHO, José Joaquim Gomes. Direito constitucional. 6. ed. Coimbra: Almedina, 1995.

CARDOSO, Eliane Gomes de Bastos; PEDRO, Nívea Simone de Freitas. Servidores Públicos: um breve estudo. Ambito Jurídico, Rio Grande, v. 14, n. 92, set 2011. Disponível em: <http:// www.ambito-juridico.com.br/site/index. php?n_link=revista_artigos_leitura\&artigo_id=10324>. Acesso em: 18 out. 2016.

CRETELLAJÚNIOR, José. Curso de direito administrativo. 13. ed. Rio de Janeiro: Forense, 1994.

DI PIETRO, Maria Sylvia Zanella. Direito administrativo. 21. ed. São Paulo: Atlas, 2008.

HESSE, Konrad. A força normativa da constituição. Porto Alegre: Safe, 2009.

MARANHÃO. Tribunal de Justiça do Maranhão. Mandado de Segurança no $\mathbf{n o 0 0 1 9 8}^{\mathbf{0}}$ 86.2015.8.10.0000. Impetrante: Itallo Lima dos Anjos. Impetrado: Secretário de Estado da Gestão e Previdência do Estado do Maranhão. São Luís, Maranhão, 4 de dezembro de 2015. Disponível em: $<\mathrm{http}$ ://tj- ma.jusbrasil.com.br/jurisprudencia/265805175/mandado-de-seguranca-ms-518542015ma-0009198-8620158100000/inteiro-teor-265805218>. Acesso em 01 nov. 2016.

MEIRELLES, Hely Lopes. Direito administrativo brasileiro. 24. ed. São Paulo: Malheiros, 1999.

MELLO, Celso Antônio Bandeira de. Curso de Direito Administrativo. 14. ed. São Paulo: 
Malheiros, 2002.

MELLO, Celso Antônio Bandeira de. Regime constitucional dos servidores da administração direta e indireta. São Paulo: Malheiros, 1990.

MELQUÍADES DUARTE, Luciana Gaspar. Revisitando o regime jurídico de Direito Público. Revista da Procuradoria Geral do Município de Juiz de Fora, Juiz de Fora, v. 1, p. 231-255, 2012.

MENDES, Gilmar. O princípio da proporcionalidade na jurisprudência do Supremo Tribunal Federal: novas leituras. Revista Diálogo Jurídico, Salvador, v. 1, n. 5, ago. 2001. Disponível em: $<$ http://www.direitopublico.com.br>. Acesso em: 18 out. 2016.

PARANÁ. Tribunal de Justiça do Paraná. Apelação cível n. 595.450-7. Apelante: Estado do Paraná. Apelado: Franciele Aparecida Silveira. Relator: Desembargadora Regina Afonso Portes. Curitiba, 28 de junho de 2010. Disponível em: <http://tj-pr.jusbrasil.com.br/jurisprudencia/19560402/ apelacao-civel-ac-5954507-pr-0595450-7/inteiro-teor-104387260>. Acesso em: 1 nov. 2016.

RIO DE JANEIRO. Tribunal de Justiça do Rio de Janeiro. Agravo interno em agravo de instrumento n. 00277719420138190000 RJ 0027771-94.2013.8.19.0000. Agravante: Josilaine Santos de Araujo de Oliveira. Agravado: Município do Rio de Janeiro. Relator: Desembargador Eduardo Gusmão Alves de Brito Neto. Rio de Janeiro, 18 de junho de 2013. Disponível em: < http:// tjrj.jusbrasil.com.br/jurisprudencia/116837433/agravo-de-instrumento-ai-277719420138190000rj-0027771-9420138190000/inteiro-teor-116837442>. Acesso em: 2 nov. 2016.

SÃO PAULO. Tribunal de Justiça de São Paulo. Apelação cível n. 0017772-60.2013.8.26.0053. Apelante: Felipe França de Araújo Paranhos. Apelada: Fazenda do Estado de São Paulo. Relator: Juiz de Direito Substituto em $2^{\circ}$ grau José Maria Câmara Júnior. São Paulo, 27 de agosto de 2014. Disponível em: <http://tj-sp.jusbrasil.com.br/jurisprudencia/136340807/apelacao-apl177726020138260053-sp-0017772-6020138260053/inteiro-teor-136340815>. Acesso em: 1 nov. 2016.

SÃO PAULO. Tribunal de Justiça de São Paulo. Apelação cível $\mathbf{n}^{\circ} \mathbf{0 0 6 4 1 4 5 2 2 2 0 1 0 8 2 6 0 0 0 0}$ SP 0064145-22.2010.8.26.0000. Apelante: Juízo "ex officio" e Fazenda do Estado de São Paulo. Apelado: Rinaldo Compri Sobrinho. Relator: Ricardo Feitosa. São Paulo, 5 de agosto de 2013. Disponível em: <http://tj-sp.jusbrasil.com.br/jurisprudencia/117570944/apelacao-apl641452220108260000-sp-0064145-2220108260000/inteiro-teor-117570954>. Acesso em: 1 nov. 2016.

SILVA, Virgílio Afonso da. O proporcional e o razoável. Revista dos Tribunais, São Paulo, ano 91, n. 798, abril, 2002. Disponível em: <http://www.revistas.unifacs.br/index.php/redu/article/ viewFile/1495/1179>. Acesso em: 19 out. 2016.

SPITZCOVSKY, Celso. Concursos públicos: limitações constitucionais para os editais. Doutrina e jurisprudência. São Paulo: Damásio de Jesus, 2004.

Como citar: ESTEVES, Diego Miranda; DUARTE, Luciana Gaspar Melquíades. Adesclassificação de candidato aprovado em concurso público tendo por base limitações de exames médicos. Revista 
do Direito Público, Londrina, v. 13, n. 3, p. 24-40, dez. 2018. DOI: 10.5433/24157-1081041.2018v13n3 p 24. ISSN: 1980-511X.

Recebido em: 24/05/2017

Aprovado em: 04/10/2018 